\title{
The Voice Conveys Specific Emotions: Evidence From Vocal Burst Displays
}

\author{
Emiliana R. Simon-Thomas, Dacher J. Keltner, Disa Sauter, Lara Sinicropi-Yao, and Anna Abramson \\ University of California, Berkeley
}

\begin{abstract}
Studies of emotion signaling inform claims about the taxonomic structure, evolutionary origins, and physiological correlates of emotions. Emotion vocalization research has tended to focus on a limited set of emotions: anger, disgust, fear, sadness, surprise, happiness, and for the voice, also tenderness. Here, we examine how well brief vocal bursts can communicate 22 different emotions: 9 negative (Study 1) and 13 positive (Study 2), and whether prototypical vocal bursts convey emotions more reliably than heterogeneous vocal bursts (Study 3). Results show that vocal bursts communicate emotions like anger, fear, and sadness, as well as seldom-studied states like awe, compassion, interest, and embarrassment. Ancillary analyses reveal family-wise patterns of vocal burst expression. Errors in classification were more common within emotion families (e.g., 'self-conscious,' 'pro-social') than between emotion families. The three studies reported highlight the voice as a rich modality for emotion display that can inform fundamental constructs about emotion.
\end{abstract}

Keywords: emotion, expression, vocal burst, vocalization

Empirical studies of emotion signaling in the face, voice, and touch have figured prominently in the central debates in affective science. Controversies surrounding the degree to which emotions are universal (Ekman, 1992; Elfenbein \& Ambady, 2002), the reliability with which emotions are signaled in distinct communicative behaviors, (Fridlund, 1994; Russell, Bachorowski, \& Fernandez-Dols, 2003) and whether less-studied states, such as embarrassment or pride, have the temporal and signal features of well-studied emotions (Keltner \& Buswell, 1997; Tracy \& Robins, 2004) attest to the central role that data on emotion signaling has played in an understanding of emotion.

It is widely assumed that emotions have distinct signals, which coordinate adaptative interactions between conspecifics (Keltner \& Kring, 1998). Closer analysis of these signals, in turn, informs an evolutionary understanding of the origins of each signal and its accompanying state. Comparisons between nonhuman primate laughter and smiling-like behavior, for example, strongly suggest that laughter and smiling - and their accompanying states amusement and joy-have distinct origins and functions (Preuschoft \& van Hooff, 1995).

Emiliana R. Simon-Thomas, Department of Psychology, University of California, Berkeley; Dacher J. Keltner, Department of Psychology, University of California, Berkeley; Disa Sauter, Department of Psychology, University College London (now at Brain and Behaviour Lab, Birkbeck College, London); Lara Sinicropi-Yao, Department of Psychology, University of California, Berkeley; Anna Abramson, Department of Psychology, Brown University.

This work has been supported by grants from the Fetzer Institute and The Templeton Advanced Research Program, sponsored by the Metanexus Institute on Religion, Science and the Humanities, with the generous support of the John Templeton Foundation.

Correspondence concerning this article should be addressed to Emiliana R. Simon-Thomas, who is now at the Institute of Personality and Social Research in the Department of Psychology at the University of California, Berkeley, 4127 Tolman Hall, Berkeley, CA 94720. E-mail: simonthomas@berkeley.edu
The human voice is a rich and nuanced source of emotional signaling, as evident in studies of the varieties of laughter (Bachorowski, Smoski, \& Owren, 2001), teasing (Keltner, Capps, Kring, Young, \& Heerey, 2001), and motherese (Fernald, 1992). Nearly half of Darwin's descriptions of the nonverbal correlates of over 40 emotion-related states include references to specific paralinguistic vocalizations_- "snorts" of contempt, "little coughs" of embarrassment, "air sucks" of high spirits, and "deep sighs" of grief (Darwin, 1872). Here, we present three studies that examine how well the human voice communicates 22 different emotions. The 22 emotions studied here do not represent a definitive nor exhaustive set of emotions with specific vocalizations. Rather, they represent a collection of states that have been examined in recent studies of face or voice, suggesting themselves as states worthy of empirical inquiry here (Matsumoto, Keltner, Shiota, O’Sullivan, \& Frank, 2008; Sauter \& Scott, 2007).

Empirical studies of emotion vocalization generally follow one of two strategies (Scherer, Johnstone, \& Klasmeyer, 2003). In a first, 'posers' recite neutral or nonsense phrases in a tone of voice, or affective prosody, that expresses a specified emotion (Banse \& Scherer, 1996). Then, these vocal stimuli are presented to 'judges,' who attempt, most typically in forced choice format, to identify the emotion conveyed. A review of 39 such studies concluded that there are distinct prosodic acoustic markers for five different emotions: fear, anger, sadness, happiness, and tenderness (Juslin \& Laukka, 2003).

A second strategy is to examine how the voice signals emotion not during speech, but during vocal bursts, which are brief, nonword utterances that arise between speech incidents. Vocal bursts include involuntary, emotion-laden, sounds like shrieks, groans, or grunts, as well as conventionalized, emblematic expressions like the enthusiastic 'yeeee-haaaw' or the breathy, awe-inspired 'whaaaaaaa,' which can potentially translate to words (Scherer, 1994). In relevant research, one vocal burst study reported $81.1 \%$ accuracy for recognizing displays of 10 different emotions: admi- 
ration, anger, boredom, contempt, disgust, elation, relief, threat, startle, and worry (Schroder, 2003). Another reported $70.1 \%$ accuracy for vocal bursts for five different positive emotions: achievement, amusement, contentment, pleasure, and relief, across two cultural groups (Sauter \& Scott, 2007).

In light of the emergent interest in positive emotion (Fredrickson, 2001) and self-conscious emotion (Tangney \& Fischer, 1995), in the present investigation we asked whether 22 different emotions could be signaled reliably with vocal bursts. More specifically, we examined whether vocal bursts communicate: (1) wellstudied, negative emotions, anger, disgust, fear, sadness, and surprise $^{1},(2)$ a less-studied negative emotion, contempt (Matsumoto \& Ekman, 2004), (3) the self-conscious emotions of embarrassment, shame, and guilt, which have been differentiated in lexical studies and in terms of facial and postural data (Keltner \& Buswell, 1997; Tangney \& Fischer, 1995), and (4) 13 positive emotional states, defined by approach and positive valence. Given the heterogeneity of vocal bursts, from the spontaneous to the conventionalized and emblematic, we recognize that the vocal burst stimuli we gathered only partially capture the breadth of vocal bursts that are likely to covary with each of the emotions studied.

Following previous conceptual analysis and empirical data, we focused our analysis of positive emotion vocal bursts on four potential families of positive emotion. One approach would be to cluster the 13 positive states into two of four families according to their placement upon the dimensions of valence and arousal, that is, low versus high arousal positive states (J. A. Russell, 1980). We chose a different route, clustering the positive emotions into emotion families according to similarities in their theorized appraisal themes and action tendencies. Contentment, desire, and sensory pleasure, for example, all fall into the family of 'savoring' emotions (Ekman, 1992).

Vocal bursts for four of the positive emotions considered here fall into the 'epistemological' family; these are states that accompany shifts in an understanding of, or knowledge about the world (Shiota, Keltner, \& John, 2006). Here, amusement (Ruch, 1993), awe (Keltner \& Haidt, 2003), interest (Marshall-Reeve, 2004) and relief were considered within the 'epistemelogical' family of emotions. The second family of vocal bursts considered is 'pro-social,' which includes expressions of emotions that orient people toward the welfare of others like compassion, gratitude, and love (Haidt, 2003; McCullough, Kilpatrick, Emmons, \& Larson, 2001). The third family of interest is 'savoring'; this includes states that involve thinking about, or experiencing, enjoyable stimuli, that is, contentment, desire, and sensory pleasure (Berridge \& Robinson, 2003; Fredrickson, 1998). Finally, we examined an 'agencyapproach' emotion family, associated with approach motivation related to past, present or anticipated actions that have led or will lead to improved rewards, both social (e.g., elevated status) and nonsocial (e.g., nutrients). Vocal bursts from the 'agencyapproach' emotion family evaluated here include enthusiasm, pride, and triumph (Tracy \& Robins, 2004). Given the preliminary nature of this line of inquiry, these families are most certainly arbitrary; clearly the emotions might cluster in other coherent ways. For example, love and desire could be clustered as a 'romantic' emotion family, awe and gratitude could be clustered as a 'spiritual' family, and so on.
Our investigation focused on two levels of analysis. First, we examined the extent to which 22 different emotions could be communicated with vocal bursts by naïve participants. We chose ordinary participants rather than trained posers or actors on the assumption that they would generate more ecologically valid vocal bursts, and thus offer a more representative assessment of the extent to which vocal bursts can communicate different emotions (Russell, 1994). Second, in light of conceptual analyses briefly reviewed above, we asked whether the signal value of different vocal bursts - that is, the extent to which they are reliably decoded by judges - cluster into the five emotion families of interest: 'self-conscious,' 'epistemological,' 'pro-social,' 'savoring,' and 'agency-approach.'

\section{Study 1: Judgment of Vocal Bursts for Negative and Self-Conscious Emotions}

\section{Method}

Vocal burst stimuli. Emotion vocal burst stimuli were gathered from 10 untrained posers (six male) during individual, 45- to 60-min appointments. Each poser was given a list of 22 emotion terms in alphabetical order; each term was accompanied by a brief descriptive scenario (Tables 1 and 3). Descriptive scenarios for each emotion were derived from conceptual analyses of the appraisals of each emotion (Lazarus, 1991; Oatley, Keltner, \& Jenkins, 2006), and translated into terms more closely resembling our posers' lay language of emotion. Posers were given time to contemplate the list of emotion terms and scenarios in anticipation of producing voiced expressions for each state without using words or word fragments. No explicit guidance was provided about which sorts of sounds posers should generate, nor were posers given examples to mimic. Posers were escorted into a private anechoic chamber (a soundproof room with no reverberation), outfitted with headphones, and positioned approximately 12 inches from a microphone. Posers then proceeded through the list of emotions and scenarios first indicating the emotion, then producing between one and five vocalizations for each emotion, at their own pace. The experimenter provided feedback throughout the vocal burst production process over a remote intercom, discouraging word or partial word use and inviting additional attempts.

Vocalizations were immediately digitized at $44 \mathrm{kHz}$ and saved onto a computer hard drive. Vocalizations that included words or were inaudible were excluded, yielding 421 vocal burst stimuli: 15 to 20 conveying each emotional state. Mean length across all 421 vocal bursts of 22 different emotions was $1.55 \mathrm{~s}$.

To make the duration of the judgment tasks tolerable and to make the lists of emotion term choices suitably complex, vocal burst stimuli were parsed into negative (anger, contempt, disgust, embarrassment, fear, guilt, sadness, shame, surprise; $n=172$ ) and positive (amusement, awe, compassion, contentment, desire, enthusiasm, gratitude, interest, love, pride, relief, sensory pleasure, triumph; $n=249$ ) stimulus sets before judging. Grouping vocal bursts into affect categories was also hypothesized to provide conservative measures of accuracy; vocal bursts within valence

\footnotetext{
${ }^{1}$ Surprise can be thought of as a neutral valence emotion (Scherer et al., 2003). We include it with the negative emotions because in facial expression studies it is reliably confused with fear (Ekman et al., 1969).
} 
Table 1

Negative Emotion Terms and Descriptive Scenarios Used to Prompt Vocal Bursts From Posers

\begin{tabular}{|c|c|}
\hline Emotion & Scenario \\
\hline \multicolumn{2}{|c|}{ Well-studied emotions } \\
\hline Anger & $\begin{array}{l}\text { You have been offended and intend to } \\
\text { defend yourself }\end{array}$ \\
\hline Disgust & $\begin{array}{l}\text { You come in contact with something } \\
\text { physically noxious or contaminating }\end{array}$ \\
\hline Fear & You are faced with physical danger \\
\hline Sadness & You experiences the loss of a loved one \\
\hline Surprise & $\begin{array}{l}\text { You find out something unexpected that } \\
\text { you didn't know }\end{array}$ \\
\hline Contempt & $\begin{array}{l}\text { You feel superior to someone because of } \\
\text { them doing something negative }\end{array}$ \\
\hline \multicolumn{2}{|c|}{ Self-conscious emotions } \\
\hline Embarrassment & $\begin{array}{l}\text { Someone discovers that you have made a } \\
\text { social gaffe }\end{array}$ \\
\hline Guilt & $\begin{array}{l}\text { You know that you have done something } \\
\text { (morally) wrong that has hurt another } \\
\text { person }\end{array}$ \\
\hline Shame & You feel like you are a bad person \\
\hline
\end{tabular}

Note. The exact terms and descriptive scenarios above were provided to posers in one alphabetized list that included both negative and positive terms. Negative emotion terms and descriptive scenarios, with pronouns and grammar changed to replace "You have ..." with "The person has ...", were read to Study 1 and 3 judges prior to commencing the negative emotion and prototype vocal burst identification tasks.

(e.g., gratitude, sensory pleasure, pride) were observed to be less different than vocal bursts across valence (e.g., fear, love, disgust, triumph). Finally, grouping vocal bursts within valence categories during the judgment tasks allowed subsequent family-wise analyses of accuracy levels within the same sample of judges, since emotion families considered here share common valence properties. The amplitudes of the original digitized vocal burst sound files were normalized within negative and positive stimulus sets to soften sharp differences in amplitude that could compromise the audibility of quieter vocalizations (e.g., fear vs. guilt).

Judgment procedures. Twenty-six judges (20 female) were recruited from a pool of undergraduate students enrolled in intro- ductory psychology courses at a large university. Informed consent was obtained in concordance with the guidelines of the Office for the Protection of Human Subjects at the University of California, Berkeley. Judges received course credit for participation. Between one and five judges participated at one time. First, the experimenter explained that the purpose of their participation was to judge whether our collection of voiced sounds expressed certain emotions. Then, the experimenter read an alphabetized list of negative emotion terms and associated descriptive scenarios (Table 1, with pronouns switched) to judges. Then, each judge was escorted into a private booth and outfitted with headphones and a response mouse connected to a computer.

Using E-Prime task presentation software (Psychology Software Tools, 2006), negative emotion vocal burst stimuli were presented one-by-one to each judge in a random sequence, with a forced choice query following each sound. First, 'Listen ...' ' was displayed on the computer screen, then, a vocal burst for any one of nine negative emotions was played into the judge's headphones. At the offset of each vocal burst, a list of negative emotion terms appeared on the screen prompting judges to select the emotion term that best matched the most recently heard sound. The response selection list included the nine negative emotion terms from the list of terms and scenarios read to them earlier, as well as a 'none of the above' option. Though the option to select 'none of the above' was included to reduce the likelihood that accuracy rates would be inflated by the forced choice format (Frank \& Stennet, 2001), vocal burst identification accuracy reported here may still reflect an advantage associated with forced choice, as opposed to spontaneous recognition formats.

\section{Results}

Across the 172 negative emotion vocal bursts, one-way analysis of variance (ANOVA) with poser sex as the independent variable and identification accuracy for each individually judged vocal burst as the dependent variable showed that judges $(n=26)$ were more accurate at identifying emotions conveyed by female than by male posers: $49 \%$ versus $42 \%$, respectively, $F(1,4470)=25, p<$ .001. Judges identified negative emotion vocal bursts from female posers an average of $12 \%$ more accurately, with the exception of

Table 2

Emotion Term Selection Rates for Vocal Bursts of Nine Negative Emotions

\begin{tabular}{|c|c|c|c|c|c|c|c|c|c|}
\hline \multirow[b]{2}{*}{ Selections } & \multicolumn{5}{|c|}{ Well-studied emotion vocal bursts } & \multirow[b]{2}{*}{ Contempt } & \multicolumn{3}{|c|}{ Self-conscious emotion vocal bursts } \\
\hline & Anger & Disgust & Fear & Sadness & Surprise & & Embarrassment & Guilt & Shame \\
\hline Anger & $79^{*}$ & & & & & & 6 & & \\
\hline Disgust & & $\mathbf{8 3}^{*}$ & & & & 7 & & & 8 \\
\hline Fear & 6 & & $37^{*}$ & & 12 & & & & \\
\hline Sadness & & & & $64^{*}$ & & & 11 & $27^{*}$ & $27^{*}$ \\
\hline Surprise & & & $46^{*}$ & & $60^{*}$ & 5 & & & \\
\hline Contempt & & & & & & $34^{*}$ & & & \\
\hline Embarrassment & & & & 5 & & & $17^{*}$ & 8 & 7 \\
\hline Guilt & & & & & & & 10 & 14 & 10 \\
\hline Shame & & & & 6 & & 5 & 11 & 15 & 13 \\
\hline NOA & & 6 & & 16 & 17 & $39^{*}$ & $33^{*}$ & $30^{*}$ & $31^{*}$ \\
\hline
\end{tabular}

Note. The values represent mean percentages of emotion term selections for negative emotion vocal bursts; none of the above (NOA) rates are shown in the bottom row. Blank cells correspond to selection rates of less than 5\%. Data in bold indicate congruence with predictions.

${ }^{*} p<.05$, chance levels set at 1 in 7 , or $14.3 \%$. 
Table 3

Positive Emotion Terms and Descriptive Scenarios Used to Prompt Vocal Bursts From Posers

\begin{tabular}{|c|c|}
\hline Emotion & Scenario \\
\hline \multicolumn{2}{|c|}{ Epistemological emotions } \\
\hline Amusement & You find something humorous \\
\hline Awe & $\begin{array}{l}\text { You feel that you are in the presence of } \\
\text { something greater than themself }\end{array}$ \\
\hline Interest & $\begin{array}{l}\text { You are curious about something and } \\
\text { want to explore it }\end{array}$ \\
\hline Relief & Some unpleasant experience ceases \\
\hline \multicolumn{2}{|l|}{ Pro-social emotions } \\
\hline Compassion & $\begin{array}{l}\text { You are moved by someone else's } \\
\text { suffering }\end{array}$ \\
\hline Gratitude & $\begin{array}{l}\text { You feel appreciative of something } \\
\text { given to you }\end{array}$ \\
\hline Love & $\begin{array}{l}\text { You are deeply affectionate towards } \\
\text { someone }\end{array}$ \\
\hline \multicolumn{2}{|l|}{ Savoring emotions } \\
\hline Contentment & $\begin{array}{l}\text { You are deeply satisfied with your } \\
\text { current condition }\end{array}$ \\
\hline Desire & You are sexually attracted to someone \\
\hline Sensory pleasure & $\begin{array}{l}\text { You are enjoying something pleasing in } \\
\text { taste or scent }\end{array}$ \\
\hline \multicolumn{2}{|c|}{ Agency-approach emotions } \\
\hline Enthusiasm & $\begin{array}{l}\text { You are looking forward to an event or } \\
\text { experience }\end{array}$ \\
\hline Pride & $\begin{array}{l}\text { You have done something that increases } \\
\text { people's opinions of you }\end{array}$ \\
\hline Triumph & You celebrate a victory \\
\hline
\end{tabular}

Note. The exact terms and descriptive scenarios above were provided to posers in one alphabetized list that included both positive and negative terms. Positive emotion terms and descriptive scenarios with pronouns and grammar changed to replace "You have ..." with "The person has ...", were read to Study 2 and 3 judges prior to commencing the positive emotion, and prototype vocal burst identification tasks.

guilt, sadness, fear, and shame, for which there was less than $4 \%$ difference in the identification of female versus male posers' vocal bursts. There were no differences in accuracy related to the sex of the judges.

Table 2 presents identification accuracy from judgments of the negative emotion vocal bursts. For all accuracy rates, binomial tests of significance were performed to ascertain the probability of obtaining accuracies observed, given chance levels of identification. Significance values are indicated by asterisk symbols in Table 2. Chance levels of accuracy were set in conservative fashion at 14.3 (1 out of 7), given the seven categories of emotion: anger, disgust, fear, sadness, surprise, and contempt, as well as selfconscious emotion (which include embarrassment, shame, and guilt) considered. This approach presupposes that accuracies for specific vocal bursts could be inflated by within-family guessing strategies, and has been used in similarly motivated studies of facial expression and touch (Frank \& Stennet, 2001; Hertenstein, Keltner, App, Bulleit, \& Jaskolka, 2006).

The well-studied emotions of anger, disgust, sadness, and surprise were well identified, replicating previous findings (Juslin \& Laukka, 2003; Schroder, 2003). Though fear vocal bursts were identified with greater frequency than chance, they were more often labeled as surprise (37\% vs. $46 \%$, respectively). Vocal bursts for contempt, a less-studied negative emotion, were identified at above chance levels, although less consistently than the wellstudied emotions. The 'self-conscious' emotions, embarrassment, guilt and shame, were identified at above chance levels, although only modestly so. As in studies of facial display (Haidt \& Keltner, 1999), vocal bursts of 'self-conscious' emotions were often judged as sadness. It is also noteworthy that for contempt, as well as the 'self-conscious' emotion vocal bursts, a significant portion of judges used the 'none of the above' classification $(>30 \%)$.

\section{Study 2: Judgments of Vocal Bursts for Four Categories of Positive Emotion}

\section{Method}

Vocal burst stimuli. Vocal bursts for the 13 positive emotions, collected as described in the method description for Study 1 (see Table 3), were used in Study 2.

Judgment procedures. The same judgment procedures that were carried out in Study 1 were carried out in Study 2, with the exception that the positive emotion vocal bursts and selection terms were presented. Two hundred forty-nine vocal bursts of 13 different positive emotions were presented to a second sample of 26 judges sex-matched to judges from Study 1 ( 20 female). After hearing each vocal burst judges selected the positive emotion term that best matched the emotion expressed. As in Study 1, Study 2 judges were presented with an alphabetized list of emotions terms matching the vocal burst categories of interest, as well as the option to select 'none of the above.'

\section{Results}

Across all 249 vocal bursts of 13 positive emotions, a one-way AVOVA with poser gender as the independent variable and identification accuracy for each vocal burst judgment as the dependent variable confirmed that greater accuracy for female posers' vocal bursts was significant: $36 \%$ versus $33 \%$, respectively, $F(1$, $6472)=4.7, p<.05$. For vocal bursts of amusement, interest, relief, compassion, love, and enthusiasm, the advantage of female posers compared to male posers was $10 \%$. For awe, contentment, desire, gratitude, and sensory pleasure vocal bursts, there was less than $2 \%$ difference in accuracy between female and male posed vocal bursts, and for pride and triumph, male posers' vocal bursts were judged $12 \%$ more accurately than were those of female posers. As in Study 1, there were no differences in accuracy related to whether judges were male or female.

Table 4 depicts the judgment accuracy for the 13 positive emotion vocal bursts evaluated in Study 2. As in Study 1, binomial tests of significance were performed, and significance indicated by asterisk symbols in Table 4 . Chance was set at 25\% (1 in 4) for the positive emotion vocal bursts to account for four families of positive emotion: 'epistemological,' 'pro-social,' 'savoring,' and 'agency-approach,' following the same conservative rationale described for determining chance levels in Study 1. Here one sees greater variability in the extent to which different positive states were communicated with vocal bursts. Judges proved to be quite adept at discriminating the vocal bursts of 3 of the 4 'epistemological' emotions: amusement, interest, and relief. The vocal bursts of awe, compassion, sensory pleasure, enthusiasm, and to a lesser extent, triumph, were also identified at rates comparable to those 
Table 4

Emotion Term Selection Rates for Vocal Bursts of 13 Positive Emotions

\begin{tabular}{|c|c|c|c|c|c|c|c|c|c|c|c|c|c|}
\hline \multirow[b]{2}{*}{ Selections } & \multicolumn{4}{|c|}{ Epistemological emotions } & \multicolumn{3}{|c|}{ Pro-social emotions } & \multicolumn{3}{|c|}{ Savoring emotions } & \multicolumn{3}{|c|}{ Agency-approach emotions } \\
\hline & Amusement & Awe & Interest & Relief & Compassion & Gratitude & Love & Contentment & Desire & Pleasure & Enthusiasm & Pride & Triumph \\
\hline Amusement & $81^{*}$ & & & & & & & & & & 9 & & 7 \\
\hline Awe & & $30^{*}$ & 6 & & & & & & & & 6 & & \\
\hline Interest & & 5 & $66^{*}$ & & & & 9 & 7 & 17 & 24 & 10 & & 12 \\
\hline Relief & & 19 & & $76^{*}$ & 9 & 6 & 9 & 11 & & & & & \\
\hline Compassion & & & & & 24 & 13 & 18 & 9 & & & & & \\
\hline Gratitude & & & & & 6 & 5 & & & & & & & \\
\hline Love & & & & & 6 & & 4 & & & & & & \\
\hline Contentment & & 8 & & & 7 & 7 & 12 & 16 & 8 & 8 & & 13 & \\
\hline Desire & & 8 & & & 11 & & 8 & 8 & 17 & 11 & & & \\
\hline Pleasure & & 10 & & & 11 & 5 & 9 & 13 & 29 & $35^{*}$ & & 7 & \\
\hline Enthusiasm & & & & & & & & & & & $42^{*}$ & & $42^{*}$ \\
\hline Pride & & & & & & & & & & & & 14 & \\
\hline Triumph & & & & & & & & & & & 19 & 7 & 29* \\
\hline $\mathrm{NOA}$ & 5 & 13 & 10 & 10 & 19 & 25 & 24 & 16 & 8 & 16 & 8 & 30 & 13 \\
\hline
\end{tabular}

Note. The values represent mean percentages of emotion term selections for positive emotion vocal bursts; none of the above (NOA) rates are shown in the bottom row. Blank cells correspond to selection rates of less than 5\%. Data in bold indicate congruence with predictions.

$* p<.05$, chance levels set at 1 in 4 , or $25 \%$.

observed in studies of the face and voice (Elfenbein \& Ambady, 2002). It was interesting that love and pride, known to have detectable signals in face and postural behavior (Gonzaga et al., 2001; Tracy \& Robins, 2004), were not reliably detected in the voice. Among the positive emotions, there were a few cases where selection rates for nontarget emotion terms were significantly greater than chance, that is, desire vocal bursts were frequently judged to be sensory pleasure or interest (17\% vs. $29 \%$ or $24 \%$, respectively) and triumph vocalizations were judged as enthusiasm ( $29 \%$ vs. $42 \%$ respectively).

\section{Study 3: Judgments of Prototypical Vocal Bursts for} Negative and Positive Emotion

\section{Method}

Vocal burst stimuli. For Study 3, a subset of the vocal burst stimuli used in Studies 1 and 2 were selected for repeat judging. First, all vocal bursts judged in Studies 1 and 2 were sorted according to mean identification accuracy. Then, the four most accurately identified vocal bursts for each emotion were selected, with the constraint that each of the four highly identifiable vocal burst were produced by two different male and two different female posers. Thus, vocal bursts with lower overall identification accuracy might have been selected over a vocal burst with higher accuracy in order to preserve poserrelated heterogeneity. The four best-identified vocal bursts originating from four different posers, two male and two female, for each emotion were identified as our prototype vocal burst stimulus set. This prototype vocal burst set, including 36 negative, and 52 positive prototypical vocal bursts was used in Study 3.

Judgment procedures. Fifty-two new judges (39 female) each performed two vocal burst identification tasks, one after the other. Tasks presented either the prototype negative or the prototype positive vocal bursts, with the same procedures and response options used in Studies 1 and 2. Negative and positive prototype vocal burst judgment tasks were presented in counterbalanced order across judges.

\section{Results}

Prototype vocal bursts of negative and positive emotions, there were no differences in accuracy related to the sex of the posers or the judges. Figure 1a depicts identification accuracy for the negative prototype vocal bursts judged in Study 3, alongside accuracy rates for the full set of vocal burst stimuli judged in Study 1 . Figure $1 \mathrm{~b}$ depicts identification accuracy for the positive prototype vocal bursts judged in Study 3, alongside accuracy rates for the full set of vocal burst stimuli judged in Study 2. This figure illustrates the breadth and boundaries of the voice's capacity to communicate different emotions.

In comparing accuracy for the full set of heterogeneous stimuli (Studies 1 and 2) to accuracy for the prototypes (Study 3), it is evident that some vocal bursts are expressed more uniformly across posers (interest: no difference in accuracy between full set and prototypes) while others were more variable between posers (awe: sizable improvement in accuracy from full stimulus set to prototypes). This may reflect the extent to which vocal bursts for different emotions are closer to more universal, automatic 'affect bursts' (amusement, anger, sadness, interest) or culturally informed, paralinguistic 'vocal emblems' (awe, contempt).

Thus far, our analyses have examined the extent to which observers could reliably judge vocal bursts of individual emotions. A second interest was to examine whether a different picture might emerge in the analyses of five emotion families: the 'selfconscious' emotions, the 'epistemological' emotions, the 'prosocial' emotions, the 'savoring' emotions, and the 'agencyapproach' emotions. Toward this aim, Table 5 depicts family-wise accuracy rates for the negative and positive emotion vocal bursts used in Studies 1, 2, and 3. Here, accuracy is defined as the use of any of the related terms from an emotion family to judge a vocal burst from that emotion family (e.g., selecting 'embarrassment,' 'shame,' or 'guilt' for any of the 'self-conscious' emotion vocal bursts). 
a

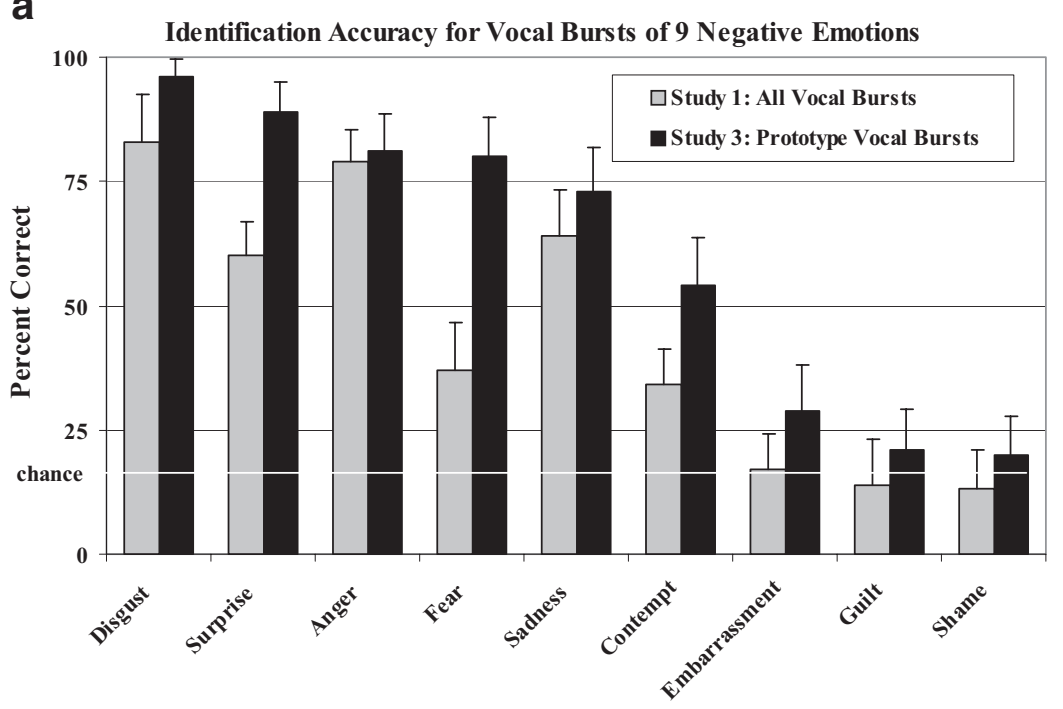

Vocal Burst Type

b

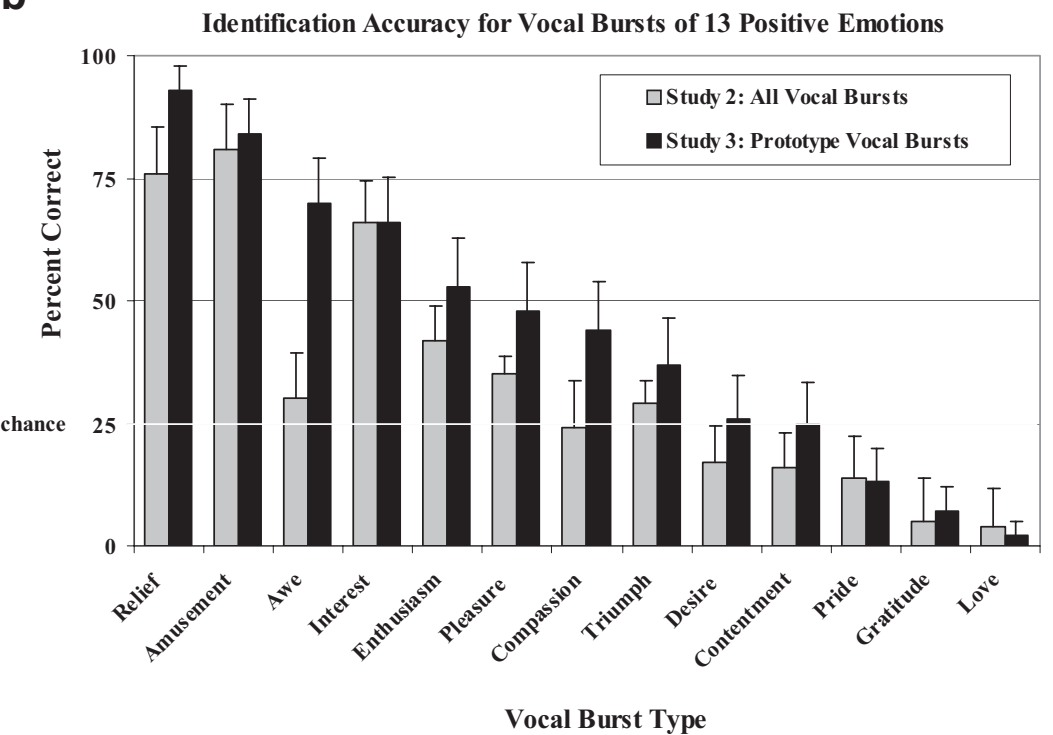

Figure 1. (a) Mean identification rates for prototypical negative emotion vocal bursts (black bars) alongside rates for heterogeneous negative emotion vocal bursts (gray bars). (b) Mean identification rates for prototypical positive emotion vocal bursts (black bars) alongside rates for heterogeneous positive emotion vocal bursts (gray bars). Chance levels are depicted with a white, horizontal line, and standard error bars are shown for each vocal burst type.

At this level of analysis, one sees a different degree to which emotions can be conveyed with vocal bursts. Judges were moderately accurate at identifying emotion from vocal bursts of individual emotions in the 'self-conscious,' 'pro-social,' 'savoring,' and 'agency-approach' families. However, at a family level, patterns of identification were more systematic. For example, judgments of prototype vocal bursts for compassion, gratitude, and love ranged from $<5 \%$ to $44 \%$ correct. Yet $47 \%$ of the time, when presented with any of these 'pro-social' vocal bursts, judges identified them as one of these three 'pro-social' emotions. Similarly, identifica- tion of prototypical vocal bursts of embarrassment, guilt, and shame ranged from $20 \%$ to $29 \%$; at the family level, they were correctly identified $47 \%$ of the time. These data lend credence to a family based approach to conceptualizing emotions.

\section{Discussion}

This investigation offers the most extensive examination to date of how many emotions the human voice can communicate. Vocal bursts were gathered from 10 untrained individuals, who were 


\begin{tabular}{cccc}
\hline Judgment study & Self-conscious & $\begin{array}{c}\text { Epistemological: change } \\
\text { in understanding of the } \\
\text { world }\end{array}$ & $\begin{array}{c}\text { Pro-social: } \\
\text { orienting towards } \\
\text { others' well-being }\end{array}$ \\
\hline $\begin{array}{c}\text { Studies } 1 \text { and } 2: n=26,172 \text { negative/ } \\
249 \text { positive vocal bursts } \\
\text { stimulation }\end{array}$ & $35^{* *}$ & $73^{* *}$ & $30^{*}$ \\
$\begin{array}{c}\text { Study } 3: n=52,36 \text { negative/52 positive } \\
\text { prototypical vocal bursts }\end{array}$ & $47^{* *}$ & $87^{* *}$ & $47^{* *}$ \\
\hline
\end{tabular}

Note. The values represent mean percentages of family-wise emotion term selections for vocal bursts of 'self-conscious' (embarrassment, guilt, shame), 'epistemological' (amusement, awe, interest, relief), 'pro-social' (compassion, gratitude, love), 'savoring' (desire, contentment, sensory pleasure), and 'status-enhancing' (enthusiasm, pride, triumph).

${ }^{*} p<.05$. *** $p<.001$.

given the task of conveying 22 different emotional states with their voice, based on theoretical descriptions of those states (Tables 1 and 3). In the first two studies, the full set of vocal bursts was presented to two groups of judges, who were asked to identify the emotions expressed by vocal bursts of negative (Study 1) or positive (Study 2) emotions. In Study 3, we presented the most well-identified vocal bursts from the first two studies, a prototype set, to new judges who were given the same forced-choice task of labeling the vocal bursts in emotion terms.

Identification of the well-studied, negative emotions-anger, disgust, fear, sadness and surprise - from vocal bursts ranged from $80 \%$ to $96 \%$ correct, corroborating existing findings (Juslin \& Laukka, 2003; Sauter \& Scott, 2007; Scherer, 1994). The three studies presented here provide the first evidence for vocal bursts of embarrassment, guilt, and shame, which were identified with low but above chance levels of accuracy, for vocal burst of awe and interest, which were readily identified, and for vocal bursts of compassion, gratitude, enthusiasm, and triumph, which were identified with low to moderate levels of accuracy. Taken together, these studies suggest that the voice can communicate at least 14 distinct emotional states without explicit words or obvious word substitutes.

With respect to the family-wise analysis of vocal burst emotion display, the present studies have several implications. First, although a family based approach to emotion has proven fruitful in understanding how individuals organize lexical terms for emotion (Shaver, Schwartz, Kirson, \& O'Connor, 1987), the data described here are the first that we know of that suggest that emotion-related behaviors cluster into conceptually coherent families. This attests to the merits of family based approaches to studying emotions (Ekman, 1992) and corroborates recent conceptualizations of positive emotion families (Shiota et al., 2006).

Specifically, our data suggest underlying commonalities within the families of 'pro-social,' 'self-conscious,' and 'agencyapproach' emotions. For example, love and gratitude vocal bursts were often identified as expressions of compassion, suggesting that they convey a more general pro-social state of affiliative intent or tenderness, as has been described in affective prosody during speech (Juslin \& Laukka, 2003). The core theme connecting the vocal bursts for these states might be the attachment system, a well-described construct that has been examined at evolutionary, behavioral and biological levels (Shaver \& Mikulincer, 2005). From an evolutionary perspective, the voice may be less privileged for articulating discrete pro-social states; pro-social states may rely on an expressive modality whose context involves greater physical proximity, like touch (Hertenstein et al., 2006).

On the other hand, for the 'epistemological' emotion family each individual emotion was well identified from its prototypical vocal bursts (amusement, awe, interest, and relief $>70 \%$ ). For this family, where the common theme is shifts in understanding or knowledge, it is intuitively plausible that the voice, also the conduit for linguistic expression of knowledge, would evolve unique displays for these states. The vocal bursts of 'epistemological' emotions may also share a common respiratory quality, an extended exhale, which might underlie valence-related or interpersonal functions of these states (Fredrickson \& Levenson, 1998). These data raise further questions about analysis of emotions at a family level. Do emotion families share a common peripheral physiological response? Are emotion families privileged toward specific expressive modalities, that is, facial expression, vocalization or touch? Do certain brain regions show common activity across families of emotional states?

With emergent bipedalism in hominid evolution, the human vocal tract elongated and the larynx expanded, morphological changes that rendered the human voice a rich source of communication (Erlich, 2000). Many of the vocal bursts documented here are likely to have emerged early in primate evolution and been retained in the human emotional repertoire. Judgment data from these vocal bursts dovetail with emotion vocalization categories described in primates, such as specific calls that indicate the presence of food (savoring) or affiliative-caregiving coos and grins (pro-social), supporting the premise that humans have evolved vocalizations of emotion for comparable communicative purposes (Snowdon, 2003). These patterns of judgment begin to clarify the quality and resolution of the human voice's capacity to communicate emotional information outside of speech.

There are methodological features of the present studies that lend confidence to our findings. The vocal bursts were provided by 10 randomly selected individuals, rather than trained actors or students of communication, as has been true of other studies of the face (Ekman, Sorenson, \& Friesen, 1969) and voice (Scherer, 1986). In Studies 1 and 2, observers judged a large and heterogeneous sample of vocal bursts (rather than those preselected for their reliability of detection, as in Study 3). Accuracy rates, therefore, reflect a more general capacity for vocal bursts to express emotions, in spite of variability related to individual posers' vocal 
qualities or expressive temperaments. Further, all three judgment studies incorporated the 'none of the above' response option, which reduces the likelihood that the accuracy rates obtained here were grossly affected by guessing strategies, which render forced choice judgment data problematic (Frank \& Stennet, 2001). Finally, our criteria for statistical significance was set using conservative thresholds for chance accuracy, that is, taking emotion families into account, rather than simply basing chance on the exact number of emotions judged. These features increase confidence in the generalizability of the present findings.

At the same time, it is important to note important limitations of the present study, which point to future areas of inquiry. Our vocal bursts were posed, and not gathered during the experience of emotion (as is true of almost all emotion judgment studies). Thus, it will be important to ascertain whether similar levels of accuracy are obtained in judgments of vocal bursts that occur during real experiences of different emotions. While our samples of judges reflect the diversity of a large public university setting, they were all of a certain age and all lived in the United States. For claims of universality, it will be essential to collect and study the signal value of vocal bursts from individuals from different cultures (Sauter \& Scott, 2007; Scherer et al., 2003). Furthermore, even with our 'none of the above' option, interpretation and generalization of accuracy rates presented here are limited by our use of a forced-choice task. A spontaneous recognition design could provide valuable supplemental information about single stimulus recognition accuracy in the domain of vocal bursts. The findings from the present study, limitations notwithstanding, reveal the voice to be perhaps the richest source of information about emotion, and new emotions such as awe and compassion, to be marked by distinct signals.

The voice is a prime modality for investigating emotion, capable of specific expression during and between speech incidents, with and without words. Here, we introduce how flexibly vocal bursts express specific states, informing basic understanding of emotion signals in social interaction and nonverbal communication.

\section{References}

Bachorowski, J. A., Smoski, M. J., \& Owren, M. J. (2001). The acoustic features of human laughter. Journal of the Acoustical Society of America, 110, 1581-1597.

Banse, R., \& Scherer, K. R. (1996). Acoustic profiles in vocal emotion expression. Journal of Personality and Social Psychology, 70, 614-636.

Berridge, K. C., \& Robinson, T. E. (2003). Parsing reward. Trends in Neurosciences, 26, 507-513.

Darwin, C. R. (1872). The expression of the emotions in man and animals (First ed. Ed.). London: John Murray.

Ekman, P. (1992). An argument for basic emotions. Cognition and Emotion, 6, 169-200.

Ekman, P., Sorenson, E. R., \& Friesen, W. V. (1969). Pan-cultural elements in the facial displays of emotions. Science, 164, 86-88.

Elfenbein, H. A., \& Ambady, N. (2002). On the universality and cultural specificity of emotion recognition: A meta-analysis. Psychological Bulletin, 128, 203-235.

Erlich, P. R. (2000). Human natures: Genes, cultures, and the human prospect. Washington, DC: Island Press.

Fernald, A. (1992). Human maternal vocalizations to infants as biologically relevant signals: An evolutionary perspective. In H. Barkow, L. Cosmides, \& J. Tooby (Eds.), The adapted mind (pp. 391-428). New York: Oxford University Press.
Frank, M. G., \& Stennet, J. (2001). The forced-choice paradigm and the perception of facial expressions of emotion. Journal of Personality and Social Psychology, 80, 75-85.

Fredrickson, B. L. (1998). What good are positive emotions? Review of General Psychology, 2, 300-319.

Fredrickson, B. L. (2001). The role of positive emotions in positive psychology. The broaden-and-build theory of positive emotions. American Psychologist, 56, 218-226.

Fredrickson, B. L., \& Levenson, R. W. (1998). Positive emotions speed recovery from the cardiovascular sequelae of negative emotions. $\mathrm{Cog}$ nition and Emotion, 12, 191-220.

Fridlund, A. (1994). Human Facial Expression: An Evolutionary View. New York: Academic Press.

Gonzaga, G. C., Keltner, D., Londahl, E. A., \& Smith, M. D. (2001). Love and the commitment problem in romantic relations and friendship. Journal of Personality and Social Psychology, 81, 247-262.

Haidt, J. (2003). The moral emotions. In R. J. Davidson, K. R. Scherer, \& H. H. Goldsmith (Eds.), Handbook of affective sciences (pp. 852-870). Oxford, UK: Oxford University Press.

Haidt, J., \& Keltner, D. (1999). Culture and facial expression: Open ended methods find more faces and a gradient of universality. Cognition and Emotion, 13, 225-266.

Hertenstein, M., Keltner, D., App, B., Bulleit, B. A., \& Jaskolka, A. R. (2006). Touch communicates discrete emotions. Emotion, 6, 528-533.

Juslin, P. N., \& Laukka, P. (2003). Communication of emotions in vocal expression and music performance: Different channels, same code? Psychological Bulletin, 129, 770-814.

Keltner, D., \& Buswell, B. N. (1997). Embarrassment: Its distinct form and appeasement functions. Psychological Bulletin, 122, 250-270.

Keltner, D., Capps, L. M., Kring, A. M., Young, R. C., \& Heerey, E. A. (2001). Just teasing: A conceptual analysis and empirical review. Psychological Bulletin, 127, 229-248.

Keltner, D., \& Haidt, J. (2003). Approaching awe, a moral, spiritual, and aesthetic emotion. Cognition and Emotion, 17, 297-314.

Keltner, D., \& Kring, A. M. (1998). Emotion, social function, and psychopathology. Review of General Psychology, 2, 320-342.

Lazarus, R. S. (1991). Emotion and adaptation. New York: Oxford University Press.

Marshall-Reeve, J. (2004). Understanding motivation and emotion. Hoboken, NJ: Wiley.

Matsumoto, D., \& Ekman, P. (2004). The relationship between expressions, labels, and descriptions of contempt. Journal of Personality and Social Psychology, 87, 529-540.

Matsumoto, D., Keltner, D., Shiota, M. N., O’Sullivan, M., \& Frank, M. G. (2008). Facial Expressions of Emotion. In M. Lewis, J. M. HavilandJones, \& L. Feldman Barrett (Eds.), Handbook of emotions. New York: Guilford Press.

McCullough, M. E., Kilpatrick, S. D., Emmons, R. A., \& Larson, D. B. (2001). Is gratitude a moral affect? Psychological Bulletin, 127, 249266.

Oatley, K., Keltner, D., \& Jenkins, J. (2006). Understanding emotions. Boston: Blackwell Publishing.

Preuschoft, S., \& van Hooff, J. A. (1995). Homologizing primate facial displays: A critical review of methods. Folia Primatology (Basel), 65, 121-137.

Psychology Software Tools, I. (2006). E-Prime (Version 1.2). Pittsburgh, PA. Ruch, W. (1993). Exhilaration and humor. In M. Lewis \& J. M. Haviland (Eds.), The handbook of emotion (pp. 605-616). New York: Guilford Press Publications.

Russell, J. A. (1980). A circumplex model of affect. Journal of Personality and Social Psychology, 39, 1161-1178.

Russell, J. A. (1994). Is there universal recognition of emotion from facial expression? A review of the cross-cultural studies. Psychological Bulletin, 115, 102-141. 
Russell, J. A., Bachorowski, J. A., \& Fernandez-Dols, J. M. (2003). Facial and vocal expressions of emotion. Annual Review of Psychology, 54, 329-349.

Sauter, D. A., \& Scott, S. K. (2007). More than one kind of happiness: Can we recognize vocal expressions of different positive states? Motivation and Emotion, 31, 192-199.

Scherer, K. R. (1986). Vocal affect expression: A review and a model for future research. Psychological Bulletin, 99, 143-165.

Scherer, K. R. (1994). Affect bursts. In S. H. M. van Goozen, N. E. van de Poll, \& J. A. Sergeant (Eds.), Emotions (pp. 161-193). Hillsdale, NJ: Erlbaum.

Scherer, K. R., Johnstone, T., \& Klasmeyer, G. (2003). Vocal expression of emotion. In R. J. Davidson, K. R. Scherer, \& H. H. Goldsmith (Eds.), Handbook of affective science (pp. 433-456). New York: Oxford University Press.

Schroder, M. (2003). Experimental study of affect bursts. Speech Communication, 40, 99-116.

Shaver, P. R., \& Mikulincer, M. (2005). Attachment theory and research: Resurrection of the psychodynamic approach to personality. Journal of Research in Personality, 22-45.
Shaver, P. R., Schwartz, J. C., Kirson, D., \& O’Connor, C. (1987). Emotion knowledge: Further exploration of a prototype approach. Journal of Personality and Social Psychology, 52, 1061-1086.

Shiota, M. N., Keltner, D., \& John, O. P. (2006). Positive emotion dispositions differentially associated with Big Five personality and attachment style. The Journal of Positive Psychology Special Issue: Positive Emotions, 1, 61-71.

Snowdon, C. T. (2003). Expression of emotion in nonhuman animals. In R. J. Davidson, K. Scherer, \& H. H. Goldsmith (Eds.), Handbook of affective science (pp. 457-480). New York: Oxford University Press.

Tangney, J. P., \& Fischer, J. W. (Eds.). (1995). Self-conscious emotions. The psychology of shame, guilt, embarrassment, and pride. New York: The Guilford Press.

Tracy, J. L., \& Robins, R. W. (2004). Show your pride: Evidence for a discrete emotion expression. Psychological Science, 15, 194-197.

Received March 11, 2008

Revision received December 16, 2008

Accepted July 23, 2009

\section{American Psychological Association SUbSCRIPTION Claims INFORMATION}

Today's Date:

We provide this form to assist members, institutions, and nonmember individuals with any subscription problems. With the appropriate information we can begin a resolution. If you use the services of an agent, please do NOT duplicate claims through them and directly to us. PLEASE PRINT CLEARLY AND IN INK IF POSSIBLE.

\begin{tabular}{l}
\hline PRINT FULL NAME OR KEY NAME OF INSTTTUTION \\
\begin{tabular}{llll}
\hline & & & \\
\hline ADDRESS & & & \\
\hline CITY & & & \\
\hline
\end{tabular}
\end{tabular}

YOUR NAME AND PHONE NUMBER

TITLE

\section{MEMBER OR CUSTOMER NIMBER (MAY BE FOUNDON ANY PAST ISSUELABEL) DATE YOUR ORDER WAS MAILED (OR PHONED)

_PREPAID CHECK CHECK/CARD CLEARED DATE:

(If possible, send a copy, fromt and back, of your cancelled check to help us in our research of your clainn.)

ISSUES: __ MISSLNG DAMAGED
NUMBER OR MONTH

Thank you. Once a claim is received and resolved, delivery of replacement issues routinely takes 4-6 weeks.

(TO BE FILLED OUT BY APA STAFF)

DATE RECEIVED:

ACTION TAKEN:

STAFF NAME:
DATE OF ACTION:

INV. NO. \& DATE:

LABEL NO. \& DATE: 